\title{
ARTICLE
}

\section{"More than Just a Student": How Curriculum Co-Creation Fosters Third Spaces in Ways of Working, Identity, and Impact}

Tanya Lubicz-Nawrocka, Moray House School of Education, University of Edinburgh, Scotland

Contact: $\underline{\text { 14775432@sms.ed.ac.uk }}$

ABSTRACT

The Third Space (Bhabha, 2004) represents non-traditional roles, processes, relationships, and spaces in which individuals work and have impact. This article presents qualitative research into 13 different curriculum co-creation initiatives at five Scottish universities and analyses the forms of Third Space that emerge. The findings highlight that curriculum co-creation can foster Third Spaces that include: new ways of working in learning and teaching, student development in a space between traditional student and teacher roles and identities, and impact in civic engagement within and beyond the university. The respect and reciprocity that characterise curriculum co-creation can greatly benefit students' personal and professional development as individuals. In addition, I suggest that the Third Space of civic engagement can advance the Third Mission of universities (beyond impact in the first two missions of teaching and research) when students and teachers work in partnership to have a positive effect on the wider society.

\section{KEYWORDS}

third space, co-creation of the curriculum, identity, student development, civic engagement

Student-staff partnerships in curriculum development have increased in recent years, resulting in many benefits to their participants (Cook-Sather, Bovill, \& Felten, 2014; LubiczNawrocka, 2017, 2018, in press; Mercer-Mapstone et al., 2017). Drawing on this work, I define curriculum co-creation as the values-based principles that guide the ongoing, reciprocal, and mutually beneficial process of staff (e.g., academic staff including tutors and lecturers, academic developers, and professional services staff) and students working in partnership to negotiate and share decision-making regarding aspects of curriculum development. I make the assumption that both staff and students are highly capable individuals who bring a wide range of different and valuable cultural, social, academic, and/or professional experience that should be drawn on in higher education to enhance the

CC-BY Licence 4.0 This is an Open Access article distributed under the terms of the Creative Commons - Attribution License 4.0 International (https://creativecommons.org/licenses/by/4.0/), which permits unrestricted use, distribution, and reproduction in any medium, provided the original work is properly attributed. 
learning and teaching experience. In this article, I explore the wider benefits of co-creation of the curriculum in the different forms of Third Space that emerge through partnership that represent new ways of viewing the non-traditional roles, processes, relationships, and spaces in which students and staff work and have impact (Bhabha, 2004; Gutierrez, 2008; Potter \& McDougall, 2017).

The concepts of student-centred, self-directed, and autonomous learning and student involvement and engagement have become established aspects of learning and teaching (Astin, 1984, 1993; Brooks \& Grundy, 1988; Kuh, Kinzie, Schuh, \& Whitt, 2005; Pascarella \& Terenzini, 1991; Shernoff, 2013). They are also foundational aspects of curriculum cocreation, which is a distinct form of student engagement because it promotes different attitudes and ways of working with students as partners in learning and teaching (CookSather et al., 2014; Mercer-Mapstone et al., 2017). Cook-Sather et al. describe this type of "partnership as a collaborative, reciprocal process through which all participants have the opportunity to contribute equally, although not necessarily in the same ways, to curricular or pedagogical conceptualisation, decision making, implementation, investigation, or analysis" (2014, pp. 6-7). Curriculum co-creation differs from other forms of learning and teaching in that the values of respect, reciprocity, and shared responsibility are central principles (Cook-Sather et al., 2014). Although students and staff may share ownership for students' learning in traditional forms of learning and teaching, co-creation of the curriculum offers the opportunity for students and staff to share ownership over aspects of not only learning but also teaching.

Like curriculum co-creation, the Third Space can facilitate what others have referred to as a zone of proximal development. For example, Vygotsky $(1978$, p. 86) used this term to describe the distance between an individual's actual development and their potential development when learning with guidance from others in problem-solving. Later, Gutierrez (2008, pp. 148-149) used this term to highlight the intentionality of creating a particular social environment for pedagogy that fosters development, equity, social justice, and cosmopolitanism that draws out individuals' sense of shared humanity whilst celebrating difference through meaningful exchanges within a learning community. The intentional nature of collaborative, interactive, respectful, and reciprocal processes of co-creating the curriculum can also promote equity while challenging the status quo of traditional structures, processes, and ways of working in higher education (Lubicz-Nawrocka, 2017). Similarly, in the work of Bhabha (2004), who originally conceptualised the Third Space, new forms of postcolonial discourse and communication can challenge traditional forms of power to foster equity and social justice. Bhabha describes how the Third Space can represent "'in-between' spaces [that] provide the terrain for elaborating strategies of selfhood-singular or communal-that initiate new signs of identity" $(2004, p .2)$. Potter and McDougall also suggest that the Third Space can push against traditional hierarchies when there is an exchange of "porous expertise.... between students' mediated cultures and the culture of the classroom...[when] the epistemological frames of reference for 'what counts' as knowledge are genuinely co-constructed" (2017, p. 85).

In this article, I explore how the concept of Third Space can provide a new lens for examining the benefits of curricular co-creation. Many benefits for students have been widely documented (Bovill \& Bulley, 2011; Cook-Sather et al., 2014; Lubicz-Nawrocka, 2017, 2018; Mercer-Mapstone et al., 2017). Here, I examine the benefits for not only individuals but also their universities and wider communities. In this respect, the notion of universities' Third Mission is relevant since it goes beyond the primary and secondary missions of 
teaching and research to highlight the important mission of contributing to social progress through civic engagement (Pinheiro, Langa, \& Pausits, 2015b; Predazzi, 2012). In describing the Third Mission, Pinheiro, Langa, and Pausits state, "In the last decade or so, calls for a reengagement of the university in helping to tackle the great challenges facing societies and local communities have propelled the Third Mission to the forefront of policy discussionsthis time under the mantra of 'relevance' and 'social impact'" (2015a, p. 227).

\section{METHODOLOGY}

This research formed part of a larger doctoral research study in which I employed qualitative methods to learn about the nuanced nature of curriculum co-creation at Scottish universities. Through criterion sampling, I identified staff members who facilitate cocreation-of-the-curriculum projects at universities in Scotland by using publications, conference presentations, and word-of-mouth since I am an active member of the University of Edinburgh community as both a PhD student and an employee. I have drawn on the work of Bovill, Cook-Sather, Felten, Millard, and Moore-Cherry (2016) to identify curriculum co-creation projects since they classify student roles in co-creation of learning and teaching as including consultants, co-researchers, pedagogical co-designers, and representatives. I identified 13 curricular co-creation projects led by 16 staff members from five Scottish universities who had previously worked with student co-creators who were pedagogical co-designers, co-researchers, or consultants. I had previously met six of the potential participants at events prior to interviewing them, and I introduced myself via email to the other potential participants. They were therefore aware of my interests in student engagement and co-creating the curriculum. Thirteen of the 16 agreed to participate in interviews. It was apparent from the staff response rate that they were proud to share and be recognised for their innovative teaching. I used snowball sampling with these staff members to identify 14 student co-creators, none of whom I had previously met, as potential participants. Eleven students agreed to participate. Student participants often shared how grateful they felt for the opportunity to co-create the curriculum with staff, and many saw participating in this research as a way of giving back to their teacher while also advancing understanding about co-creation of the curriculum.

The 13 curriculum co-creation projects within the Scottish higher education sector that formed the context of my study varied widely and took place across various subject areas. These ranged from medicine and veterinary studies to science (geoscience and biology) to social sciences (political science, sociology, social work, and education). Some of the projects were extracurricular and students were specially selected to participate; these included students serving as external consultants helping staff improve teaching and learning, and student-staff partners co-creating educational resources. Other projects included the whole class in graded courses, through co-creation of grading criteria, cocreation of aspects of assessment such as exam questions, negotiated peer teaching embedded into graded courses, and co-creation of a variety of community projects. In particular, staff at different universities supported students to prepare for and implement teaching projects at local primary schools, service learning projects, and science outreach projects with community partners.

I made the aims of the study and the voluntary nature of participation transparent through using participant information sheets and consent forms. In most cases, I conducted semi-structured interviews on a one-to-one basis with participants. However, at one university, it was deemed most appropriate to hold a focus group discussion with four 
participants, since three staff members and one student had worked together closely on a project. During the interviews and focus group with co-creation practitioners-both staff and students - I explored topics that included their experiences of working in partnership and their beliefs concerning the benefits and challenges of curriculum co-creation.

Interviews tended to last around an hour, with some staff interviews and the focus group discussion extending longer. With permission from each participant, I audio-recorded and transcribed the interviews and focus group discussion.

Drawing on a constructivist grounded theory approach (Charmaz, 2006, 2014), I analysed the extensive qualitative data, identifying themes using the constant comparative method and NVivo software. I engaged in reflective journaling following many of the interviews which I used to help validate the trustworthiness of the data. I also used triangulation since, across the majority of the 13 co-creation initiatives, I interviewed both staff co-creators and corresponding student co-creators. Although the Third Space was not central to the focus of this study and participants did not mention the Third Space concept by name, the theme did arise from the data, with participants highlighting how their work as co-creators was distinct from traditional teaching and learning. Based on my inductive analysis, the findings highlight that co-creating the curriculum can foster three different types of Third Spaces including new ways of working in learning and teaching, student development in a space between traditional student and teacher roles and identities, and impact through civic engagement within and beyond the university. I will now explore each of these themes.

\section{RESULTS}

\section{The Third Space "zone of proximal development" of new ways of working in learning and teaching}

A key aspect of curriculum co-creation is staff intentionally sharing responsibility with students for some forms of teaching decision-making, often with the aim of promoting student development and equity. This pedagogy of co-creating the curriculum can be seen as a zone of proximal development (Bhabha, 2004, p. 86; Gutierrez, 2008, p. 148) that develops a cosmopolitan learning environment in which students and staff bring different forms of expertise to the development-focused experience that brings them together. For example, participants in this study who worked together to co-create the curriculum at one university (including Staff 11, 12, 13, and Student 11) describe co-creation as "Where you don't know who is the teacher and who is the student," since they share responsibility. Student 11 expands on this definition:

It was about how everybody would come with some skills or some knowledge and it would all go towards one goal. We tried to get that as much as possible. ...l think it's where you know that you can learn from each other and you can move forward in creating something good for both of you, more than just your own individual use... I think it is about openness on both sides.

The process of developing both individual and collective responsibility as well as the reciprocal nature of learning from each other are key aspects of sharing ownership in curriculum co-creation.

Participants describe the processes and dialogue that come from sharing ownership over aspects of course design. Staff 4 (who works with fourth-year students to teach 
second-year students by embedding peer teaching into parts of the credit-bearing curriculum) says:

Teaching is like an iceberg because students don't usually see the nine tenths that are underwater with all the preparations. We throw the whole thing over to them and give them the tools.

This teacher highlights how the co-creation experience of supporting peer teaching helps fourth-year students learn about the workload involved in preparing for teaching. Similarly, Staff 8 describes the challenges that students learned to overcome when each group designed and led a two-hour seminar within their co-created course:

Course design is a complicated thing. We tried as much as possible to let them see the nuts and bolts of the process, and how these things get devised...They could do whatever they wanted with it [their seminar], but then what was interesting is things like time management and structuring often became very problematic. My view is you have got to figure it out yourself, because that is what we do [as teachers]. I think a lot of them found that very useful in the sense that I don't think they have ever had that kind of experience where they had to take ownership...We could go back and say "well these are the kinds of things that we grapple with when we design courses."

As also highlighted in other studies, curricular co-creation helps students learn about the course design process (Bovill \& Bulley, 2011; Breen \& Littlejohn, 2000; Cook-Sather et al., 2014) and develop empathy for teachers (Hermsen, Kuiper, Roelofs, \& van Wijchen, 2017; Lubicz-Nawrocka, in press). Similarly, this participant reflects on the benefits of students cultivating transferrable skills and attributes throughout the co-creation experience. By gaining experience of planning and teaching a seminar, student co-creators acquire rich learning experiences in a supportive learning environment whilst also developing resilience and empathy for the challenges that staff face.

Different curriculum co-creation projects facilitate sharing different amounts of ownership and power with students. However, the openness and willingness of both students and teachers who participate in co-created projects demonstrates the reciprocity of co-creation of the curriculum. This is often a new way of working that students need to adjust to as they become more confident in their contributions. For example, Staff 6 reflects:

I do think they find it difficult at first because it is more democratic and it's them taking responsibility.

In addition to students taking ownership over course development and their own learning, curriculum co-creation can also promote different ways of working when students become more confident in valuing their contributions. Several participants focus on how, during co-created projects, students share their expertise on how they learn best which helps staff improve their teaching. Student 11 describes the process of recognising the expertise that she brings to co-creation: 
I remember feeling very afraid of why I was supposed to be there, because I felt like I was speaking to people with a lot more knowledge and a lot more titles than me. But it was about realising that you were not supposed to have that kind of knowledge or that kind of expertise; that was not your role. Your role was as the student, so you were expert in being a student and nobody could take that away from you. It was about discussing different perspectives, and what comes out of all those different perspectives is something amazing that is going to bring you forward in so many different ways.

This significant quotation shows how student participants adapt to a co-creation experience that values their viewpoints and brings together different forms of expertise to facilitate a reciprocal learning experience in which staff can learn more from students.

Other participants emphasise that breaking down barriers between traditional student and staff roles helps contribute to strong working relationships during curriculum cocreation. Student 4 speaks about working collaboratively as a student consultant in learning and teaching:

The first time I did the project, it was completely new and the staff were also learning at the same time. That was positive, I think, because it helped to know everyone was in the same boat. Even although they were the specialists in this area, it was nice to know there wasn't an "us and them" divide.

This student describes the respect and trust that is built within co-creation of the curriculum projects when both staff and students are in new learning environments. This can make working relationships more equitable, since not only students but also staff are seen as learners. Similarly, Staff 11 speaks about how co-creation can help move teachers and students away from hierarchical relations:

It was the first time a lecturer has ever asked them for their view and basically said "well how would you do it?"... Not being the famous "sage on the stage," if you like, just breaking down barriers...It is a problem, you solve the problem. Your solutions are equally as important...Partnerships work because people are bringing different things to them.

These participants show how co-creation can bridge the gap between student and staff roles while they engage in new experiences and solve complex problems together, which I will explore further in the next section. This helps students to gain a better understanding that knowledge is not fixed and to feel they have valuable viewpoints to contribute to its development. Although students and teachers bring different knowledge, expertise, and skills which should each be valued, participants emphasise that partnerships are most successful when individuals bring different attributes and perspectives. Therefore, co-creating the curriculum can develop a Third Space where staff and students challenge traditional hierarchies in higher education by promoting new ways of working that intentionally create particular learning environments that foster shared responsibility, equity, reciprocity, and empathy. 


\section{The Third Space for students" identities "in-between" traditional student and teacher roles}

For some students, co-creating the curriculum has a transformative effect, particularly with respect to their increased confidence, as well as personal and professional development. In this respect, the Third Space of co-creating the curriculum can develop what Bhabha calls "'in-between' spaces...that initiate new signs of identity" (2004, p. 2). Almost all student participants in this study emphasise that co-creating the curriculum was the most influential and positive aspect of their university experience since, at times, sharing responsibility led to an intermediate role between those of traditional students and staff. Despite this challenge, all student participants taking co-created courses unanimously highlighted these as the best courses throughout their entire degree programme.

Staff 8 shares how students' development of skills throughout their university degree may be an important aspect of the success of co-creation projects:

You need to have a certain degree of buy-in from the people who are doing it... I think it also requires a certain level of experience, being able to deal with faculty and various different people, navigate different power relationships, be able to take on feedback and criticism constructively.

This teacher highlights students' high levels of motivation, engagement, commitment, and maturity which are important aspects that facilitate sharing ownership of the curriculum. Other participants highlight the opportunity-and the challenge-of entering a Third Space in which students' expertise is valued by staff. For example, Student 3 reflects broadly on resistance from some staff members to curriculum co-creation, and how she developed stronger communication skills in her role as a student consultant to work effectively with staff partners to improve teaching and learning:

It's really hard to do and... to have reached a level of partnership and skill for that to happen... It's quite a sophisticated conversation to talk about their impact on a group of fellow students.

This student describes the higher-order skills and attributes required for students to work effectively in successful partnerships with staff, who also need to be open to and respectful of students' input. It can be difficult at times for students to give staff constructive feedback, and for staff to receive this feedback positively. However, the development of trust and a shared vision helps student partners enter a new kind of space that is less hierarchical and where they can feel that their expertise is valued.

Many staff members reflect on the transformative nature of co-creation for students. For example, Staff 9 describes:

I think it's been a great course, and we've really seen a transformational effect on the students involved. That's certainly what they're telling us that there's a lot of value added...It really made them incredibly active and reflexive.

Students' development as reflective and active learners who can articulate their leadership skills and other transferrable skills are powerful benefits of curriculum cocreation that can be transformative for students. Other staff participants share that co- 
creating the curriculum helps students consolidate and recognise the value of their wider higher education experience. Staff 8 says:

A lot of them started to see for the first time the value of their degree, which was always there but it was making explicit some things that are probably a bit more implicit in their degree. A lot of them were having interviews at the time and...they could talk more coherently about what it was that they were doing that translated into other areas of life.

The process of reflecting on their skills throughout curriculum co-creation helps many students recognise more clearly and articulate the skills they develop throughout their undergraduate degree, which can also benefit them beyond university.

Furthermore, although Student 8 works on a separate curriculum co-creation project with different staff partners, his reflections echo those above:

Although lots of courses over the course of four years at university have helped me develop, I'd say this course has actually given me probably the most applicable skills in terms of applying it to jobs outwith the university. It's actually taking responsibility for a project and having to just go and do it outwith the university, with minimal assistance. It's very different to anything else I've done at uni... I think in terms of engaging with the lecturers and the client as well, it made you feel a bit more than just a student which was nice: it made you feel almost on an equal playing field.

This student shares how co-creating the curriculum is a very different learning experience that helped him recognise his transferrable skills. It is striking that he identifies this learning opportunity as the one most beneficial in his employability and job applications. This statement also highlights important aspects of students feeling as though they are entering a Third Space which is "almost on an equal playing field" as staff members in taking responsibility for a project. Student 8 , like others above, shares how co-creating the curriculum can contribute to students' development when they embrace responsibility as confident contributors who enter a Third Space in-between traditional student and staff roles and identities as both learners and teachers.

\section{The Third Space of "porous expertise" and civic impact within and beyond the university}

Many participants share how co-creating the curriculum is transformative not only for individual students but also for the wider student body and even the wider community. Potter and McDougall (2017, p. 85) describe how excellent teachers can embrace students' porous expertise in a Third Space where the co-construction of knowledge gained inside and outside the classroom can be combined to generate authentic, meaningful new ways of knowing. I would like to take this concept further to suggest that porous expertise can also encompass students and staff working with community partners and applying their knowledge to solve problems that have civic impact within and/or beyond the university. For example, Staff 11 describes the benefits of sharing responsibility with students during curriculum co-creation: 
You see major changes when you work closely with them, but you also see that reverberating around the student body. The context of leadership is a really important one because you do see people taking ownership and control and also encouraging others to do the same... I think that is the legacy of that ownership: It is not just about learning partnership, it is about developing autonomous learning skills, and the ability and the willingness to take on challenges and not balk at them... [student co-creators] are not willing to just sit there and be told things anymore. They want to do things.

This participant highlights the impact of co-creating the curriculum on developing students' leadership skills, independent and critical thinking skills, resilience, and willingness to embrace challenges by contributing actively to the university community. In this same vein, Student 10 who participated in a partnership project at a different university reflects:

I think it taught me to challenge authority a bit more... It meant that now, going into the workplace and the wider world, I know just because someone has a higher status than me, it doesn't mean I'm unimportant. I can still challenge them and I should still have the confidence to question things and not just take things because I'm on a lower level than them. When I got my job...I had the power to negotiate and have the authority to say what I want...[Previously] I definitely put myself in a box and accepted that I am this level therefore I can't do this. We always say we can't do this but actually they're just imposed rules.

In addition to developing communication and negotiation skills, this student emphasises the self-respect and confidence she gained to become more assertive and independent without feeling intimidated by power. She acknowledges the transformative nature of the co-creation experience which helped her contribute actively and challenge authority where necessary.

Other students describe how co-creation of the curriculum transformed their perception of their abilities as a student. Student 8, who co-created a project for a local community partner, describes:

It felt like you were able to take responsibility and actually have an impact and the work you were doing was making a bit of a difference basically... It genuinely was one of the best courses I've done in the university. It's nice to do something a bit different and to get out of the very small academic sphere and actually give back to the community.

This participant highlights not only her enjoyment of this co-created project but also the rewarding nature of applying her knowledge and skills to contribute to the wider community. Furthermore, Student 7 adds:

In the very beginning, [our teacher] said, "We have students who are studying something. They're a resource, why doesn't the community use it?" I think that's a great way of looking at it, and it teaches us that we have something to offer. You think you're a student: You're just paying to understand the world a bit better, but now you actually realise that what you know is something valuable and the world can benefit from it. 
These student co-creators speak about how sharing decision-making responsibilities with staff helps students to feel more motivated to learn and engage, and they recognise what they can contribute to the wider community.

Furthermore, Student 11 shares reflections on the effect of co-creation as a transformative experience for her:

It makes you grow as an individual beyond the university skills and beyond everything you can learn in the classroom... because projects can actually go towards developing the institution and programmes in the community.

Many student co-creators describe the rewarding nature of their co-creation-of thecurriculum projects from which they personally benefitted, using words such as "lucky" and "grateful" to speak about these rare experiences in higher education, from which many of their peers do not have the opportunity to benefit. In addition, students speak about the value of their projects, which contribute to the rest of the university and the wider society. For example, Student 10 states:

I feel really lucky to be part of that actually... I guess you feel like what you're learning is really relevant to your life rather than just something you can put in your short-term memory and forget about once the exam is over or an essay is over which happens quite a lot [elsewhere in traditional teaching]...[But with co-creation of the curriculum] everything I've learned, that's for the rest of my life and I know that people will be benefiting from it in years to come.

These students appreciate the fulfilling opportunities to co-create the curriculum as they think about the long-lasting impact of these experiences on their own development. They also highlight how these opportunities have allowed them to have a wider, positive impact through sharing their work with the community.

Both student and staff participants in this section highlight the skills and attributes that have contributed to making curriculum co-creation a transformative experience for students. However, many of the students speak about the benefits of a wider impact, which helps them demonstrate that they are responsible and professional contributors to wider society. Staff 3 sums up well the characteristics that students often come to embody while co-creating the curriculum. She reflects:

There's a recognition of professionalism, and that it is a sensitive relationship that comes with responsibility. They also need to realise that their work goes beyond themselves and they're having an impact on the institution.

Therefore, co-creation of the curriculum can facilitate a Third Space of porous expertise (Potter \& McDougall, 2017) that helps students recognise the value of their professional contributions and how they can transform their student engagement into civic engagement that benefits their wider community.

\section{DISCUSSION}


The findings presented above indicate how respect, reciprocity, and empathy between students and teachers can facilitate a new way of working in a Third Space characterised by what Gutierrez (2008), drawing on Vygotsky's terminology, calls a zone of proximal development. Shared responsibility and reciprocity are themes that are prevalent throughout the students-as-partners literature, and they are noted for fostering student development, equity, and social justice. For example, Cook-Sather et al. (2014) highlight how the values of respect, reciprocity, and shared responsibility, which are central to partnerships in learning and teaching, have transformational potential for individuals and institutions. This is echoed in other literature showing how partnerships can advance a more socially just, inclusive, and democratic pedagogy (Bovill, Morss, \& Bulley, 2009; Bron, Bovill, \& Veugelers, 2016; Healey, Flint, \& Harrington, 2014; Lubicz-Nawrocka, 2018, in press; Mercer-Mapstone et al., 2017).

Curriculum co-creation can foster new ways of working that focus not just on the product of academic success but also on the rich processes of learning and teaching (Boomer, 1992; Bron et al., 2016; Cook-Sather et al., 2014; Fraser \& Bosanquet, 2006; Lubicz-Nawrocka, in press; Matthews, 2016). The Third Space can represent a different way of working in learning and teaching, based on professional relationships that are created in new spaces that are more democratic and reciprocal. For instance, Bhabha highlights the uncertainty resulting from changing cultural power dynamics and suggests that the development of hybridity within the Third Space "breaks down the symmetry and duality of self/other, inside/outside" (2004, p. 165). In the current study, we have also seen how cocreation of the curriculum promotes new ways of working in which "there wasn't an 'us and them' divide" and how "Not being the famous 'sage on the stage'. . . [led to] breaking down barriers." However, sharing responsibility can be a "complicated," "difficult," and perhaps an intimidating experience which may be new for both students as well as for staff. Cocreation can not only pose the aforementioned challenges and risks but, similarly to the Third Space of hybridity of cultures, also destabilise academic hierarchies (Bryson \& Furlonger, 2018; Hancock \& Lubicz-Nawrocka, 2018; Lubicz-Nawrocka, 2017; Marquis, 2018; Woolmer, 2018). However, these challenges are often mitigated by the benefits that come from strong working relationships, recognition of different forms of expertise, and the focus not just on educational products and outcomes but also on the process of the partnership journey. Figure 1 shows how curriculum co-creation facilitates a collaborative learning environment that promotes new ways of working in higher education in a Third Space that is distinct from traditional structures and processes.

This leads us to the second theme of the current study: student transformation to become "more than just a student." The resulting effect of co-creation of the curriculum is that it can break down hierarchical barriers to balance reciprocal student/teacher relationships (Dyer \& Lubicz-Nawrocka, 2019). Students' personal and professional development during curriculum co-creation can be striking in many cases (Cook-Sather et al., 2014; Mercer-Mapstone et al., 2017) and can facilitate student and staff partners learning from each other whilst developing self-authorship (Baxter Magolda, 1999; LubiczNawrocka, 2018).

Figure 1: A Third Space of new ways of working in curriculum co-creation 


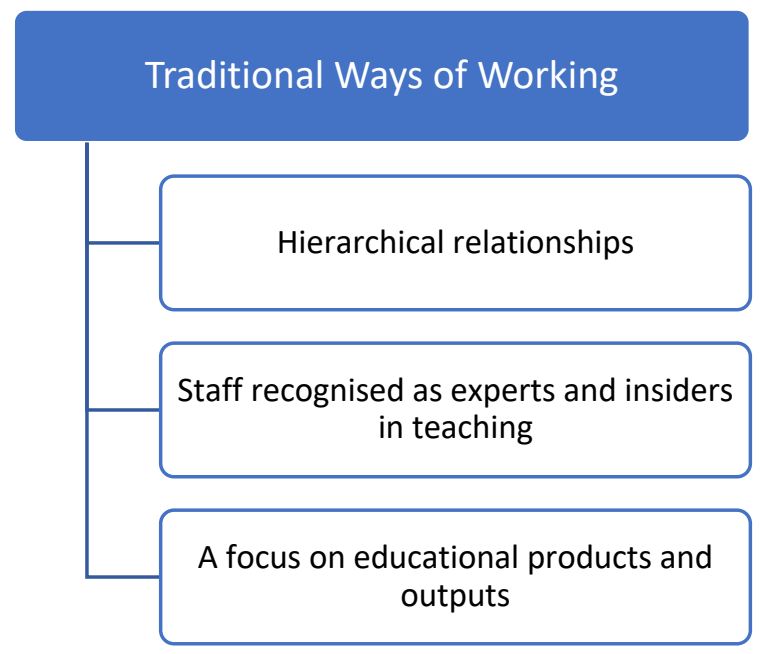

Third Space of New Ways of Working

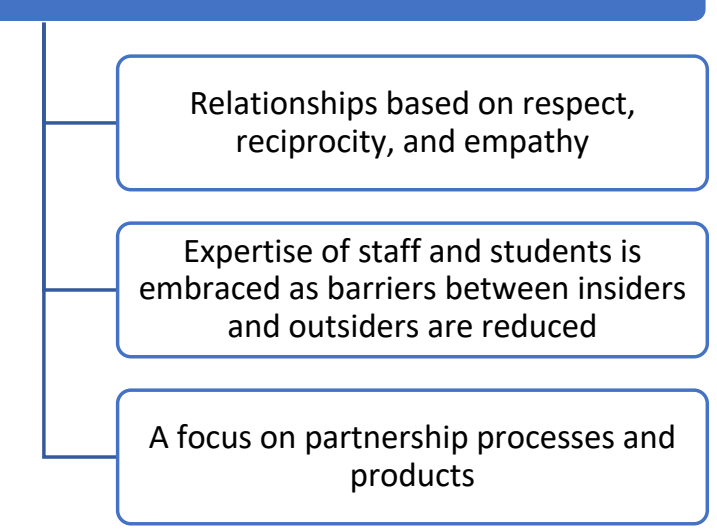

As we have seen in this study, many student co-creators develop attributes such as confidence and resilience, as well as a number of transferrable skills such as critical thinking, communication, negotiation, teamwork, and leadership. This can foster rewarding, creative learning and teaching experiences that are enjoyable for both students and teachers as they reflect on students' transformation as individuals (Bovill, 2017; Bovill, Bulley, \& Morss, 2011; Gee, 2003; Lubicz-Nawrocka, 2017, 2018, in press; Mercer-Mapstone et al., 2017). As a result, students' identities can develop in a Third Space in between traditional student and staff roles. Figure 2 shows how respect, reciprocity, and more equitable working relationships in curriculum co-creation help students become empowered as they take on responsibilities that are in between traditional student and staff roles and identities in higher education.

\section{Figure 2: A Third Space of new student roles as empowered individuals who take responsibility to co-create curricula}

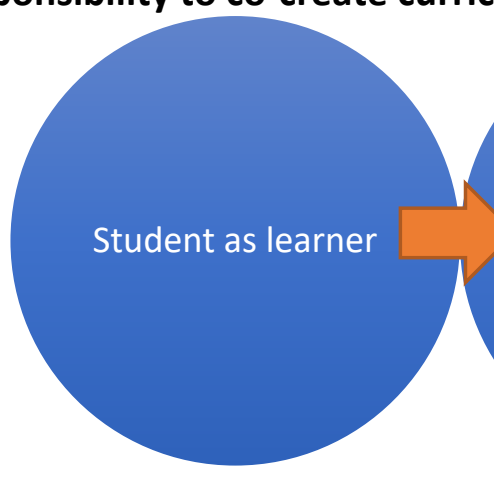

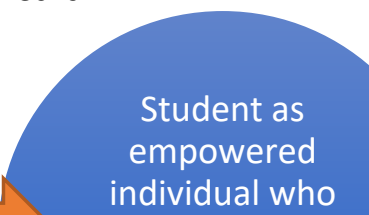

takes responsibility

for learning and

aspects of decision-

making in teaching

What is most striking, perhaps, is the effect of curriculum co-creation not only on advancing students' development but also on their positive impact in their communities. Cocreation of the curriculum welcomes students' porous expertise (Potter \& McDougall, 2017) from their lived experience into the classroom, and it also facilitates opportunities for students to work on projects that benefit their communities within and beyond the university campus. The rich qualitative data suggests that students' empowerment in a role between student and staff responsibilities can support their contributions as leaders who engage democratically to have civic impact. The findings presented here suggest an impact of curriculum co-creation on the wider community beyond the "ivory towers" of higher 
education institutions (Lempert, 1996). This suggests contributions to a Third Mission of universities in addition to their primary and secondary missions of teaching and research.

During co-created projects, when students and staff realise that students have something to offer to help solve local and/or global challenges, they recognise how, as one participant suggests, "their work goes beyond themselves." Students and staff can bring their different perspectives and expertise while working together towards solving these challenges facing their communities. Co-creation of the curriculum has been found to foster critical and democratic engagement by focusing on the processes of curriculum negotiation within co-created academic communities (Boomer, 1992; Bron et al., 2016; Fraser \& Bosanquet, 2006; Lubicz-Nawrocka, 2018). Furthermore, Scandrett et al. (2010) and Crowther, Hemmi, and Scandrett (2012) have shown how a co-created course had a positive impact on community activists' engagement in the wider society as they effected social change. Curriculum co-creation can foster a Third Space of civic engagement that facilitates the exchange of porous expertise (Potter \& McDougall, 2017) to benefit not only individuals but also their university and wider communities. Therefore, I suggest that curriculum cocreation of the curriculum can facilitate three different types of Third Space that have a positive impact on individuals' identities through their development, on higher education institutions through offering new ways of working, and on communities beyond the university through contributions to their Third Mission (see Figure 3).

\section{Figure 3: Curriculum co-creation can impact positively on three types of Third Space}

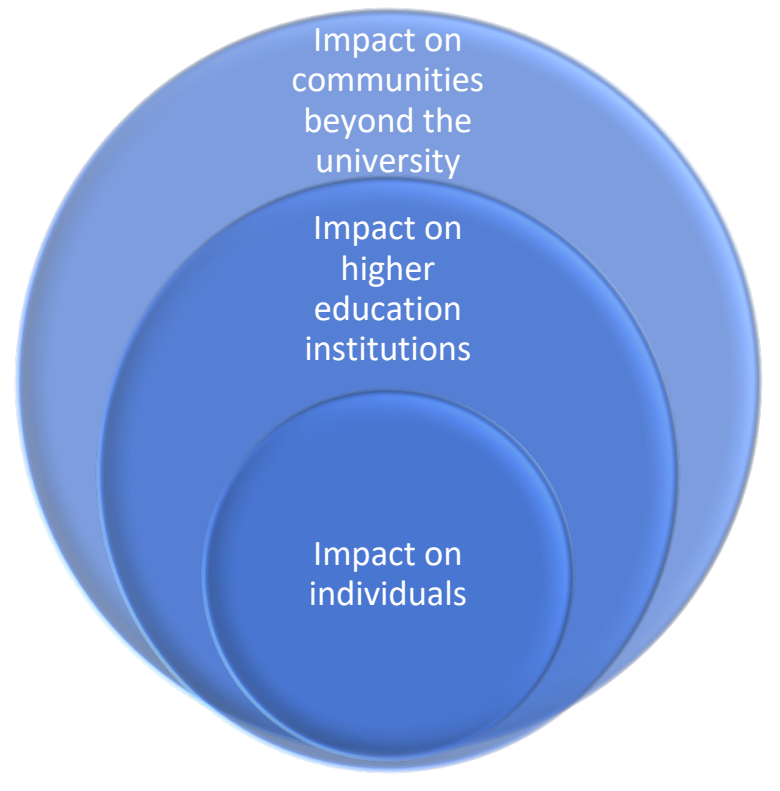

\section{CONCLUSION}

The research findings presented above highlight that curriculum co-creation can foster development of three different types of Third Spaces including: a zone of proximal development of new ways of working in learning and teaching, students' identities "inbetween" traditional student and teacher roles, and porous expertise of civic impact within and beyond the university. While focusing in this article on the impact of curriculum cocreation on students, the transformational potential for staff is a fascinating theme which I have begun to address (see e.g., Lubicz-Nawrocka, 2018) but it is widely acknowledged that this area needs considerable further research (Mercer-Mapstone et al., 2017). 
The three different forms of Third Space stemming from curriculum co-creation work can be transformational when students demonstrate professionalism, expertise, and ownership. This finding has implications not only for students' employability, but also for their capacity to have a positive impact on society. In addition, the Third Space of civic engagement in co-creating the curriculum is significant for advancing the Third Mission of universities when students and staff recognise that students' work has the capacity to benefit not only themselves or those in academia, but also their wider communities.

This research was reviewed according to the Moray House School of Education (University of Edinburgh) research ethics committee guidelines and received Level 1 ethical approval.

\section{NOTE ON CONTRIBUTOR}

Tanya Lubicz-Nawrocka is a PhD student at the University of Edinburgh. Her doctoral research focuses on student empowerment through student-staff partnerships in co-creating the curriculum and analysing the impact of these partnerships on individuals and their communities.

\section{REFERENCES}

Astin, A. (1984). Student involvement: A developmental theory for higher education. Journal of College Student Development, 40(5), 518-529.

Astin, A. (1993). What matters in college? Four critical years revised. San Francisco, CA: Jossey-Bass.

Baxter Magolda, M. (1999). Creating contexts for learning and self-authorship: Constructivedevelopmental pedagogy. Nashville, TN: Vanderbilt University Press.

Bhabha, H. K. (2004). The location of culture (Routledge Classics ed.). London, UK: Routledge.

Boomer, G. (1992). Negotiating the curriculum. In G. Boomer, N. B. Lester, C. S. Onore, \& J. Cook (Eds.), Negotiating the curriculum: Educating for the 21st century (pp. 4 - 14). London, UK: Falmer Press.

Bovill, C. (2017, October 5). Recapturing the excitement of lectures [Web log post]. Retrieved from http://www.teaching-matters-blog.ed.ac.uk/?p=2005

Bovill, C., \& Bulley, C. J. (2011). A model of active student participation in curriculum design: Exploring desirability and possibility. In C. E. Rust (Ed.), Improving Student Learning (ISL) 18: Global theories and local practices: Institutional, disciplinary and cultural variations (pp. 176 - 188). Oxford, UK: Oxford Brookes University.

Bovill, C., Bulley, C. J., \& Morss, K. (2011). Engaging and empowering first-year students through curriculum design: Perspectives from the literature. Teaching in Higher Education, 16(2), 197-209. https://doi.org/10.1080/13562517.2010.515024

Bovill, C., Cook-Sather, A., Felten, P., Millard, L., \& Moore-Cherry, N. (2016). Addressing potential challenges in co-creating learning and teaching: Overcoming resistance, navigating institutional norms and ensuring inclusivity in student-staff partnerships. Higher Education, 71(2), 195-208. https://doi.org/10.1007/s10734-015-9896-4

Bovill, C., Morss, K., \& Bulley, C. (2009). Should students participate in curriculum design? Discussion arising from a first year curriculum design project and a literature review. Pedagogical Research in Maximising Education, 3(2), 17-25. 
Breen, M. P., \& Littlejohn, A. (2000). The significance of negotiation. Cambridge, UK: Cambridge University Press.

Bron, J., Bovill, C., \& Veugelers, W. (2016). Students experiencing and developing democratic citizenship through curriculum negotiation: The relevance of Garth Boomer's approach. Curriculum Perspectives, 36(1), 15-27.

Brooks, A., \& Grundy, P. (1988). Individualization and autonomy in language learning. London, UK: Modern English Publications.Retrieved from https://www.teachingenglish.org.uk/sites/teacheng/files/F044\%20ELT54\%20Individualization\%20and\%20Autonomy\%20in\%20Language\%20Learning v3.p $\underline{\mathrm{df}}$

Bryson, C., \& Furlonger, R. (2018). A shared reflection on risk in trying to work with students in partnership. Teaching and Learning Together in Higher Education, 1(24), 1-7.

Charmaz, K. (2006). Constructing grounded theory: A practical guide through qualitative analysis. London, UK: Sage Publications.

Charmaz, K. (2014). Constructing grounded theory (2nd ed.). London, UK: Sage Publications.

Cook-Sather, A., Bovill, C., \& Felten, P. (2014). Engaging students as partners in learning and teaching: A guide for faculty. San Francisco, CA: Jossey-Bass.

Crowther, J., Hemmi, A., \& Scandrett, E. (2012). Learning environmental justice and adult education in a Scottish community campaign against fish farming. Local Environment, 17(1), 115-130. https://doi.org/10.1080/13549839.2011.646970

Dyer, S., \& Lubicz-Nawrocka, T. (2019). Using play to facilitate faculty-student partnership: How can you co-design a module? In A. James \& C. Nerantzi (Eds.), The Power of Play in Higher Education: Creativity in Tertiary Learning. Cham, Switzerland: Palgrave Macmillan.pp-299-301

Fraser, S., \& Bosanquet, A. (2006). The curriculum? That's just a unit outline, isn't it? Studies in Higher Education, 31(3), 269-284. https://doi.org/10.1080/03075070600680521

Gee, J. P. (2003). What video games have to teach us about learning and literacy. New York, NY: Palgrave Macmillan.

Gutierrez, K. (2008). Developing a sociocritical literacy in the Third Space. Reading Research Quarterly, 43(2), 148-164. https://doi.org/10.1598/RRQ.43.2.3

Hancock, J., \& Lubicz-Nawrocka, T. (2018). Creating spaces: Embracing risk and partnership in higher education. Teaching and Learning Together in Higher Education, 1(24), 1-7.

Healey, M., Flint, A., \& Harrington, K. (2014). Engagement through partnership: students as partners in learning and teaching in higher education. Retrieved from https://www.heacademy.ac.uk/engagement-through-partnership-students-partnerslearning-and-teaching-higher-education

Hermsen, T., Kuiper, T., Roelofs, F., \& van Wijchen, J. (2017). Without Emotions, Never a Partnership! International Journal for Students as Partners, 1(2), 1-5. https://doi.org/10.15173/ijsap.v1i2.3228

Kuh, G. D., Kinzie, J., Schuh, J. H., \& Whitt, E. J. (2005). Assessing conditions to enhance educational effectiveness: The inventory for student engagement and success (1st ed.). San Francisco, CA: Jossey-Bass.

Lempert, D. (1996). Escape from the ivory tower: Student adventures in democratic experiential education. San Francisco, CA: Jossey-Bass.

Lubicz-Nawrocka, T. (2017). Co-creation of the curriculum: Challenging the status quo to embed partnership. The Journal of Educational Innovation, Partnership and Change, 3(2). https://doi.org/10.21100/jeipc.v3i2.529 
Lubicz-Nawrocka, T. (2018). Students as partners in learning and teaching: The benefits of co-creation of the curriculum. International Journal for Students as Partners, 2(1), 47-63. https://doi.org/10.15173/ijsap.v2i1.3207

Lubicz-Nawrocka, T. (in press). Creativity and collaboration: An exploration of empathy, inclusion, and resilience in co-creation of the curriculum. Student Engagement in Higher Education Journal.

Marquis, E. (2018). Embracing and/or avoiding the risks of partnership: A faculty perspective. Teaching and Learning Together in Higher Education, 1(24).

Matthews, K. E. (2016). Students as partners as the future of student engagement. Student Engagement in Higher Education Journal, 1(1).

Mercer-Mapstone, L., Dvorakova, S. L., Matthews, K. E., Abbot, S., Cheng, B., Felten, P., Knorr, K., Marquis, E., Shammis, R., \& Swaim, K. (2017). A systematic literature review of students as partners in higher education. International Journal for Students as Partners, 1(1). https://doi.org/10.15173/ijsap.v1i1.3119

Pascarella, E., \& Terenzini, P. (1991). How college affects students. San Francisco, CA: JosseyBass.

Pinheiro, R., Langa, P. V., \& Pausits, A. (2015a). The institutionalization of universities' third mission: Introduction to the special issue. European Journal of Higher Education, 5(3), 1-6. https://doi.org/10.1080/21568235.2015.1044551

Pinheiro, R., Langa, P. V., \& Pausits, A. (2015b). One and two equals three? The third mission of higher education institutions. European Journal of Higher Education, 5(3), 1-17. https://doi.org/10.1080/21568235.2015.1044552

Potter, J., \& McDougall, J. (2017). Digital media, culture and education: Theorising Third Space literacies. London, UK: Palgrave Macmillan.

Predazzi, E. (2012). The third mission of the university. Rendiconti Lincei, 23(Supplement 1), 17-22. https://doi.org/10.1007/s12210-012-0182-4

Scandrett, E., Crowther, J., Hemmi, A., Mukherjee, S., Shah, D., \& Sen, T. (2010). Theorising education and learning in social movements: Environmental justice campaigns in Scotland and India. Studies in the Education of Adults, 42(2), 124-140. https://doi.org/10.1080/02660830.2010.11661593

Shernoff, D. J. (2013). Optimal learning environments to promote student engagement. New York, NY: Springer.

Vygotsky, L. S. (1978). Mind in society: The development of higher psychological processes. Cambridge, MA: Harvard University Press.

Woolmer, C. (2018). Exploring dimensions of risk in pedagogical partnerships in higher education. Teaching and Learning Together in Higher Education, 1(24). 